\title{
The development and operation of the United Kingdom's air quality management regime
}

\author{
J. W. S. Longhurst, J. G. Irwin, T. J. Chatterton, E. T. Hayes, \\ N. S. Leksmono \& J. K. Symons \\ Air Quality Management Resource Centre, \\ University of the West of England, Bristol, UK
}

\begin{abstract}
This paper considers the development and operation of the UK's air quality management regime since its introduction in the Environment Act, 1995. In the context of a changing and challenging air pollution climate, the development of an effects-based, risk management system for air quality regulation is evaluated. Key to the regime is the division of responsibility between central government and local government for both the diagnosis of areas of poor air quality and for the development of solutions to improve air quality.
\end{abstract}

Keywords: environment act, 1995, air quality management, United Kingdom.

\section{Management in historical perspective}

The United Kingdom (UK) has a long history of attempts to control air pollution. Initially attention was focused on the problem of smoke control in wintertime conditions as typified by the London Smog of $1952[1,2]$ where air pollution was principally determined by patterns of coal consumption. The subsequent government appointed Beaver Committee [1] investigation into the causes, consequences and future control measures led to the introduction of the Clean Air Act, 1956. Regulatory attention was given to domestic sources primarily through this Act which required that domestic coal be burnt in approved appliances which were more efficient, and gave encouragement to the use of smokeless fuels and to other forms of fuel switching such as from coal to oil, gas or electricity. Following the introduction of the Act coal consumption declined in domestic and industrial markets throughout the 1960s and 1970s and the frequency and severity of coal smoke pollution within the UK's towns and cities 
progressively decreased. The primary control measure applied by local authority regulators was the designation of an area known as the 'smokeless zone' by issuing a smoke control order under the powers granted by the Act. In a smokeless zone, only specified fuels could be burnt, and grants were available to assist owners or occupiers to convert coal fires to allow them to use smokeless fuel.

The relatively slow timescale taken for these measures to be fully implemented should be noted; for example some large metropolitan areas did not complete their smoke control programmes until the early 1980s [3,4]. The effect of these control measures on smoke and $\mathrm{SO}_{2}$ concentrations was pronounced, with significant and sustained reductions in concentrations being recorded across Great Britain as the measures were progressively applied. For example, in Manchester the annual mean concentrations of smoke fell by some 90 percent between 1959 and 1984. The bronchitic death rate - an indicator of the health effect of air pollution - reduced in line with the concentration of smoke [4].

Successful control of smoke and $\mathrm{SO}_{2}$ in urban areas, regulation of lead in petrol and continuing downward pressure on industrial air pollution undoubtedly led to a prevailing view in the 1980 s that urban air pollution was being successfully managed. In the 1980s and early 1990s the scale of the growth in road traffic and consequent emissions, allied with increasing public concern about possible health impacts, found the UK regulatory regime ill-prepared for the challenge of managing the impacts of vehicle related air pollution [5].

\section{Developing an effects based air quality framework}

In 1990, the UK Government set out its environmental strategy in the White Paper "This Common Inheritance" [5]. In the area of air quality, this recognised the growing concern over health effects and announced the establishment of an Expert Panel on Air Quality Standards (EPAQS). This was established with a remit to assess, on the basis of the best available epidemiological information, the public health impact of current UK air pollutant concentrations and to recommend a UK Standard for the protection of public health from named pollutants. An essential question in the risk assessment process undertaken by EPAQS was to identify the concentration and time interval over which adverse effects could occur, and to make recommendations to the Government taking account of uncertainties in the evidence base.

During the 1980s and early 1990s the UK had reasonably good air quality but was susceptible to occasional episodes of poor air quality which tended to occur with greater frequency and severity in heavily populated and industrialised areas. Typical examples of such episodes are the December 1991 London episode and the December 1994 episodes in Manchester, Birmingham and London [7]. Partly due to these episodes air quality began to receive increasing policy attention in the 1990s as public concern grew over the health impacts of air pollution [8].

The existing management framework and available policy tools were found to be inadequate for tackling these continued urban pollution episodes. Different. 
emission sources were controlled by separate government departments and their associated agencies, resulting in a system of control that lacked co-ordination and integration particularly at the local scale. The Government response outlined in "This Common Inheritance" [6] was to explore mechanisms for a new approach which would make more effective use of air quality control mechanisms in an integrated and holistic way.

A new philosophy for air quality control was presented which built upon the existing technology-based controls by adding an effects-based, risk management approach founded on the new Air Quality Standards set by EPAQS. The new framework was introduced in the Environment Act 1995 (Part IV, Air Quality) which set out responsibilities for central and local government. Local control and management was placed at the heart of the response whilst maintaining, at a national level, a critical role in co-ordination and direction of local actions and the undertaking of such duties most effectively discharged at the level of the nation state. In Northern Ireland local authorities shadowed the process of LAQM until the Environment (Northern Ireland) Order, 2002 came into force and gave them equivalent responsibilities to their British counterparts.

\section{Policy and practice in LAQM 1995-2005}

The primary requirement of the 1995 Environment Act was the preparation of an Air Quality Strategy (AQS) by Government. The AQS was first published in 1997, and reviewed, updated and amended in 2000 and 2007 (with an Addendum in 2003). The AQS considered the historical legacy of air pollution, the contemporary nature of the air pollution challenge, and the adequacy of current controls, measures and priorities and laid out a new direction for the management of air quality in compliance with the requirements specified in the Environment Act (see [5,8-10]). Together, the Environment Act, 1995 and AQS provide a framework in which national and local actions are required to identify and remediate areas of poor air quality. The Act places a series of duties and responsibilities upon local authorities to review and assess local air quality against specific targets known as air quality objectives [9]. The original AQS was founded upon the principles of sound science, health effects based regulation, cost-effectiveness, proportionality, sustainability, precautionary approach and subsidiarity which to this day continue to inform its implementation.

The AQS sets out a series of air quality objectives for LAQM covering lead, $\mathrm{CO}, 1,3$-butadiene, $\mathrm{SO}_{2}, \mathrm{NO}_{2}$, benzene and $\mathrm{PM}_{10}$. These objectives were introduced as Regulations in 1997, revised in 2000 and amended 2002. A new AQS was published in 2007 [10]. This latest AQS does not remove any of the objectives set out previously but signals a change in approach to the management of particulate matter by introducing what is termed an 'exposure reduction' philosophy. This reflects opinion that there is no accepted threshold for health effects due to exposure to fine particles. This 'exposure reduction' approach has been adopted as a more efficient way to achieve future reductions in the health 
effects of air pollution by providing a driver to reduce concentrations across the UK rather than just in a small number of localised hotspots [10].

The objectives specified in Regulations represent the Government's judgement of achievable air quality by 2010 on the evidence of costs and benefits and technical feasibility. The objectives apply in areas where the public may be exposed for the averaging time of the relevant objective such as building facades, public open spaces, pavements and gardens. Objectives are not exceeded if there is no relevant public exposure and local authorities undertaking assessments of air quality are under a duty to identify if public exposure exists in any area where exceedence of an air quality objective is identified [8]. Local authorities are then required to declare areas where relevant exposure and exceedence of the objectives exist as Air Quality Management Areas (AQMAs). AQMAs are similar in concept to the idea introduced in the Clean Air Act, 1956 of a smokeless zone, although in practice they are more complex entities as they can relate to a wider number of pollutants. Following declaration of an AQMA a local authority is required to develop an Action Plan to pursue the achievement of the air quality objectives detailing both the measures to be taken and the timescale for their implementation.

The Environment Act places a duty on Government to support local authorities through the provision of guidance and other initiatives. This has included the development of high quality national monitoring networks, the creation of $1 \mathrm{~km}$ resolution emissions inventories, the provision of training for local authority personnel, the development of Technical and Policy Guidance to assist local authorities in their LAQM duties, and the provision of additional financial assistance to help authorities purchase monitoring equipment and other technical resources. An important support element has been the development of web, telephone and email help desks and other support materials [8] to assist, often non-specialist, air quality officers in carrying out their duties.

The AQS is dynamic and subject to rolling review to reflect developments in European legislation, technological and scientific advances, improved air pollution modelling techniques and an increasingly better understanding of the socio-economic issues involved in managing air quality and implementing effective Action Plans [8]. Similarly, the Air Quality Regulations, which give statutory weight to the air quality objectives, are reviewed periodically to reflect new developments in knowledge and understanding of specific pollutants and their impact on human health.

In parallel with UK developments, the EU has continued its development of strategic air quality management including the Air Quality Framework Directive (96/62/EC) and subsequent daughter directives. As new Daughter Directives emerge these are transposed into UK legislation and, subject to the scale and complexity of the management challenge implied by the Directive they may be incorporated in to the requirements of LAQM. Local authorities have the responsibility to work towards securing the objectives through the process of review and assessment and through the development of action plans. Under the Act Local authorities carry out reviews and assessments of air quality to define the contemporary and future state of local air quality in their area. This work is 
considered by Government to be a continuous process and local authorities are encouraged to consider it as such, although there are distinct phases of work known as Rounds. During each Round, the Government exercises its power as a Statutory Consultee to appraise the work of local authorities and acts to assure itself that the statutory duties of the local authorities are being undertaken in an appropriate manner.

Local authorities in Great Britain began the process of Review and Assessment in 1998. The first round of the process concluded in 2001 and resulted in some 129 local authorities declaring one or more AQMAs. A second round of Review and Assessment began in 2003, and a third round commenced in 2006. In the interval between Rounds local authorities are required to issue an annual Progress Report, the purpose of which is to report new monitoring data, describe any new developments that might affect air quality and to maintain the momentum of air quality management in the local authority.

At the end of Round 2, some 192 local authorities had declared AQMAs and by the summer of 2008 more than 200 UK local authorities had one or more AQMAs. These AQMAs have principally been declared for $\mathrm{NO}_{2}$, with a significant number of $\mathrm{PM}_{10}$ and $\mathrm{SO}_{2}$ declarations. An AQMA represents the conclusion of a technical assessment of air quality carried out in accordance with central government guidance against the air quality objectives. In declaring an AQMA a local authority will have satisfied itself, relevant stakeholders and Government that a risk of exceeding one or more objectives by the date the objective is to be achieved has been demonstrated in an area in which public exposure for a relevant period is or will be present. Details of local authorities with AQMAs may be seen at http://www.airquality.co.uk/archive/laqm/ laqm.php. Figure 1 provides a time series of AQMA declarations in the UK.

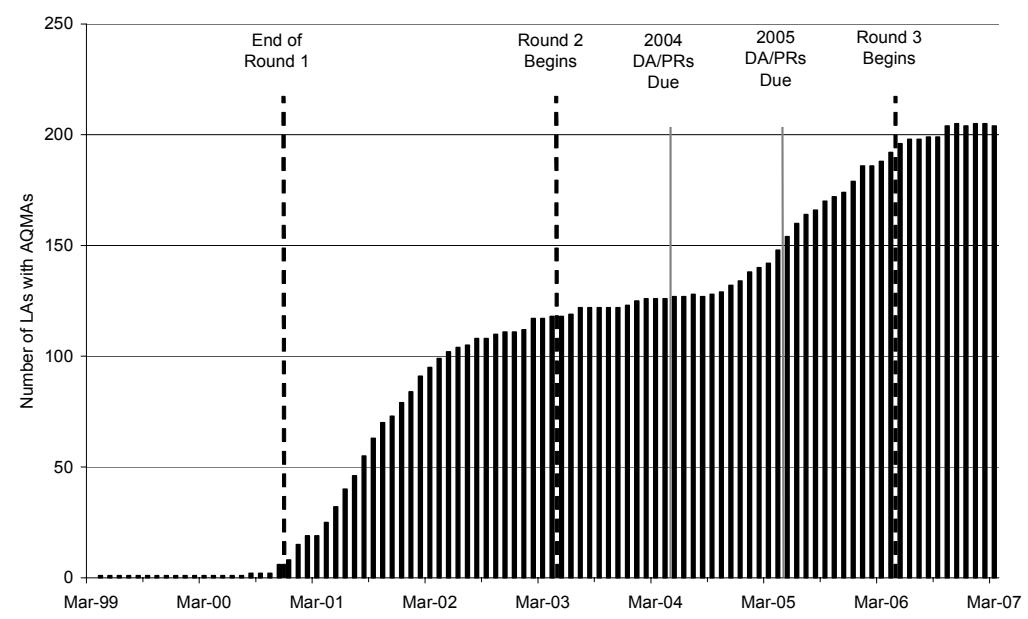

Figure 1: Number of local authorities with air quality management areas. 
Following the declaration of an AQMA, a local authority must undertake a Further Assessment of air quality as required by Section 84 of the Environment Act. This is designed to confirm the appropriateness of the original decision, define the boundaries of the declared area and provide information on the emission sources contributing to the exceedence in order to support the preparation of an Action Plan. Following the declaration of an AQMA, the local authority is required to develop an Action Plan under section 84 of the Act. Although the Act does not specify a timescale for this Policy Guidance states that this is expected within 12 to 18 months of the designation of the AQMA [11]. In practice, the development of plans has proceeded at a slower rate than the technical Review and Assessment work. Even where a plan is being implemented there are limited examples of success to report. By the summer of 2007, some 122 local authorities had produced an Action Plan and details of the current situation may be seen at http://www.airquality.co.uk/archive/laqm/ actionplan.php. Given the complexity of the contemporary air quality challenge with political, economic, public opinion and technical barriers to overcome this lack of significant progress is perhaps not surprising and it could be seen as reflecting a reluctance of society to adapt behaviour in order to achieve environmental goals. Changes in policy set out in the UK White Paper on Local Government [12] have meant that English local authorities with AQMAs associated with emissions from transport sources have been able to incorporate their Action Plans into their Local Transport Plan (LTP) process, a separate Government requirement operating to a different reporting timescale to that of LAQM. Despite these resulting administrative issues, the integration of LAQM and LTP offers the prospect of a more holistic approach within a local authority for the remediation of poor air quality. Importantly, local authorities that integrate their Action Plans into the LTP are eligible to receive funding under the LTP settlement grant to support the combined Action Plan.

\section{Concluding remarks}

The journey from an exclusively source-control approach to a complex but integrated, risk management effects-based process of air quality management has been a lengthy one. It has resulted in an integration of European, UK and local policies, strategies, regulation and action in order to improve air quality in the places where it matters most. Having evolved a comprehensive air quality management system it is important to note that the dynamic nature of the management challenge requires that the system continues to be periodically evaluated and renewed. This happens through regular reviews of the AQS, routinely assessing the challenges posed by poor air quality and determining the most appropriate management response to the problems identified using inter alia the principles of sound science, proportionality and risk assessment. This calibrated response enables actions to be appropriately targeted at the local level when evidence suggests that this is both effective and efficient at delivering improvements in air quality "hot spots", whilst reserving for national application 
and action those elements of policy and management best discharged at the level of the nation state. This is in line with the principle of subsidiarity.

The LAQM process has been refined over a series of rounds of activity dating back to the late 1990s and is now a routine activity for local authorities who have become capable and competent in discharging their air quality responsibilities. The outcome of their efforts is an efficient process for the identification of areas of poor air quality and the quantification of the temporal and spatial domain of these areas. If the judgement of effectiveness is taken as solely an improvement in air quality resulting from the application of the process then the system might be considered to be ineffective. However, this would not be a fair assessment. The development and implementation of Air Quality Action Plans has not as yet had the anticipated effect on local air quality. This outcome is not surprising if one considers the nature of the countervailing forces of growth in road traffic, commerce and industry that often lie wholly or in part outside of local authority control.

The LAQM process is administrated by Defra and the Devolved Administrations through local authority Environmental Health or other Environmental Service departments. In practice, most of the sources of air pollution are related to the remits of the transport, land-use planning or economic development areas of local government and there is little direct ability for the review and assessment process to have a strong effect on these policy areas [9]. In the preparation of Action Plans the Environmental Health department will undertake negotiations with transport, land-use planning or economic development areas of local government in order to align, as best as is possible, the air quality resolution within existing policies and processes of governance. Where the local authority has control over the sources of pollution and has been able to establish effective internal and/or external co-ordination and communication systems between different functions, then significant air quality improvements can be seen at the local level even if they do not always succeed in reducing pollution levels to below the objective concentrations.

The current UK approach to the management of air quality, particularly at the local level, can be seen as a strong example of a public health orientated environmental management programme, setting out a risk-based framework, leading to targeted, proportionate and cost-effective actions focussed on a single area of the environment. There are clear health-based standards, indicating 'acceptable' and 'unacceptable' levels of air pollution. National policy objectives have been set based on these standards but taking into account technical and economic issues that might affect their attainment. This provides clear target dates for their achievement within a framework allowing assessment of problems at both local and national levels.

In the 11 years of LAQM since the first air quality strategy was published in 1997 there has been a significant enhancement in the ability of decision makers to take account of air quality in routine decision making. The quality of information available to decision makers has improved as the LAQM process has developed appropriate methods for local, repetitive, comprehensive, and quality assured review and assessment procedures. These reviews and assessments are 
able to draw upon high quality emissions and monitoring data via a number of specially commissioned web resources and support structures guiding the LAQM process. Local authorities have begun the difficult transition from simply defining the state of the local atmosphere towards securing AQAP goals. This represents a transition from procedural compliance with the process of LAQM towards achievement of improved air quality outcomes. They are doing this through new means of internal communication and co-operation and external consultation.

Whilst some of the processes and procedures used need refinement and enhancement to become fully effective, overall the position does provide encouragement that the continuing challenge posed by poor air quality will continue to be managed efficiently and effectively. The flexible, responsive system, which has created a strong flow of information between national and local government, in both directions, is at the heart of the difference between contemporary air quality management and traditional strategies of pollution control.

The Air Quality Management regime will evolve in the period covered by the new AQS [10]. Particularly important, will be the introduction of exposure reduction as a means to increase public health protection. This new policy initiative will itself bring new challenges for implementation but offers the promise of maximising public health gains at spatial scales greater than local areas of non-compliance with numerical objectives. However, the overall regime must continue to sit within the framework of sustainable development, and must take better account of social equity and environmental justice concerns. A critical issue for the further development of air quality management policy and practice will be to ensure appropriate integration with policies and strategies for the management of greenhouse gases.

\section{References}

[1] Brimblecombe, P. The Big Smoke. A history of air pollution in London since medieval time, Routledge, 1987.

[2] National Society for Clean Air. The Clean Air Revolution 1952 -2052. National Society for Clean Air. Brighton, 2002.

[3] Longhurst, J.W.S., Lindley, S.J., Conlan, D.E., Rayfield, D.J. \& Hewison, T. Air quality in historical perspective. Urban Air Pollution III. eds Power, H. \& Moussiopoulos, N. CMP: Southampton, pp.69-109, 1996.

[4] Manchester Area Council for Clean Air and Noise Control, 25 Year Review. MACCANC, Manchester, 1982.

[5] Longhurst, J.W.S., Lindley, S.J., Watson, A.F.R., Conlan, D.E. The introduction of local air quality management in the United Kingdom. A review and theoretical framework. Atmospheric Environment 30, 39753985, 1996

[6] HM Government. This Common Inheritance, CM 1200. Her Majesty's Stationery Office: London, 1990 
[7] Elsom, D.M., Smog. More than a London Problem. The Clean Air Revolution 1952 -2052. National Society for Clean Air: Brighton, pp 13 18, 2002.

[8] Longhurst, J.W.S., Beattie, C.I., Chatterton, T.J., Hayes, E.T., Leksmono, N.S. \& Woodfield, N.K., Local Air Quality Management as a risk management process: assessing, managing and remediating the risk of exceeding an air quality objective in Great Britain. Environment International 32, 934-947, 2006

[9] Beattie, C.I., Longhurst, J.W.S., Woodfield, N.K. Air quality management: evolution of policy and practice in the UK as exemplified by the experience of English local government. Atmospheric Environment 35, 1479-1490, 2001.

[10] Department for Environment, Food and Rural Affairs. The Air Quality Strategy for England, Scotland, Wales and Northern Ireland, Volume 1. Defra: London, 2007.

[11] Department for Environment, Food and Rural Affairs Local Air Quality Management Policy Guidance LAQM.PG(03), Defra: London, 2003. 